\title{
Bio-economic management strategy evaluation of deepwater stocks using the FLBEIA model ${ }^{\star}$
}

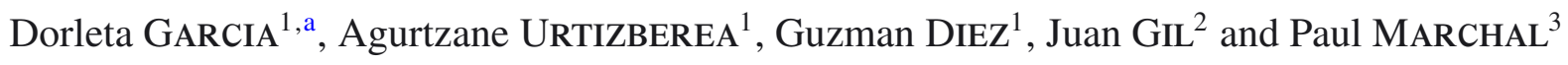 \\ 1 Marine Research Division, AZTI-Tecnalia, Txatxarramendi s/n, 48395 Sukarrieta, Bizkaia, Spain \\ 2 Instituto Español de Oceanografía Centro Oceanográfico de Cádiz, Puerto Pesquero, Muelle de Levante s/n, 11006 Cádiz, Spain \\ 3 IFREMER, Channel and North Sea Fisheries Department, BP 699, 62321 Boulogne-sur-mer, France
}

Received 12 February 2013; Accepted 16 October 2013

\begin{abstract}
Deepwater fish are characterized by long lifespans, late maturity and low productivity. This implies slow recovery from low biomass levels and it is, therefore, important to manage these stocks correctly to avoid overfishing. However, these stocks are generally data poor, which it makes difficult to apply quantitative assessment models on which to base their management. The management strategy evaluation (MSE) approach consists in evaluating the performance of management strategies by simulation before their implementation. In the evaluation, the main sources of uncertainty in a fishery system and its management process should be taken into account in order to find robust management strategies. Thus, the MSE approach is relevant to the management of data-poor stocks. We used the FLBEIA software, an FLR library coded in the R statistical language, to conduct a bio-economic impact assessment of fisheries management strategies. We evaluated the performance of several management strategies in three different deepwater case studies using the MSE approach: beaked redfish (Sebastes mentella) in the Norwegian Sea, blackspot seabream (Pagellus bogaraveo) in the Strait of Gibraltar, and French mixed deepwater fisheries in the North East Atlantic. In conclusion, we found that the $S$. mentella stock is very sensitive to the stock recruitment relationship chosen. For $P$. bogaraveo, simulations showed that the present constant catch management is as good as more sophisticated strategies. Finally, in mixed fisheries, case study fleet dynamics were key for the success of management strategies
\end{abstract}

Keywords: Bio-economic modelling / Deep-sea fisheries / Harvest control rules / Management strategy evaluation / Norway / Bay of Biscay / Gibraltar / Atlantic Ocean

\section{Introduction}

Management of deepwater stocks is very important within fisheries science communities to ensure the sustainable use of marine living resources exploited by deepwater fisheries, and thus prevent significant adverse impacts on deepsea vulnerable marine ecosystems (VMEs) and for the protection of marine biodiversity that these ecosystems contain (FAO 2009). There is no agreed worldwide definition that characterizes deepwater ecosystems. The United Nations Food and Agriculture Organization (FAO) defined "deepwater" as those sea areas with depths below $200 \mathrm{~m}$ and ICES (2005) uses the term "deepwater fisheries" for those fisheries that are active in depths below $400 \mathrm{~m}$. The definition of "deepwater fish species" is problematic because some species living in deep-waters are also distributed along the continental shelves (Gordon 2003). Furthermore, biological identification criteria are problematic because some of the stocks living in deep waters exhibit

\footnotetext{
* Supporting information is only available in electronic form at www.alr-journal.org

a Corresponding author: dgarcia@azti.es
}

life history characteristics comparable to those in shallower waters. Recently, for North East Atlantic, the DEEPFISHMAN Consortium ${ }^{1}$ defined deepwater species as those that have more than $50 \%$ of adult biomass located at depths below $200 \mathrm{~m}$, or that spend more than $50 \%$ of their expected lifetime at depths below $200 \mathrm{~m}$.

The fish species inhabiting deepwater sea areas show low natural mortality rates, extended longevity, slow growth rates, late maturity and spawning that may not occur every year (FAO 2009). As a consequence of these characteristics, deepwater species show relatively low productive capacity, which makes them particularly vulnerable to overexploitation and means that the recovery of their populations from low levels of biomass could be very slow. Hence, it is particularly important to avoid overexploitation in these ecosystems.

Many of the assessment shortcomings for deepwater stocks are the same as for data-poor stocks. A common problem in the assessment of these stocks is the absence of information about life history parameters (growth, maturity and natural

1 EU FP 7 DEEPFISHMAN project (Grant agreement No. 227390) - Management and Monitoring of Deep-sea Fisheries and Stocks. 
mortality) and population structure of the stocks (Bailey et al. 2009) In the NE Atlantic, data availability is generally poor and usually only time-series of the total landings are available (Villasante et al. 2012). Reliable abundance indices are rarely available; meaning that even the simplest assessment models, like surplus production or tuned virtual population analysis (VPA) models, do not give credible stock abundance estimates. For most of the deepwater stocks in the NE Atlantic, biological reference points (BRP) and harvest control rules (HCR) have never been defined as part of the management. In this sense, International Council for Exploration of the Sea (ICES) (1998) and FAO recommended to use the limit and precautionary reference points suggested for data-poor situations (Caddy 1998).

Internationally, the main tools for deepwater stock management are total allowable catches (TACs) and quotas. However, in regions such as the Mediterranean Sea, these stocks are managed using effort restrictions. Effort and TAC-based management are usually combined with other management tools, such as mesh size limitations, bycatch limits, closed areas/seasons or vessel/gear licensing (Large 2012).

In the NE Atlantic, EU TAC for 46 deepwater species listed in the Annex I and Annex II (EC 2002a) were established in January 2003 This regulation was complemented by the introduction of an EU Access Regime establishing specific access requirements (EC 2002b). However, in the 22 species listed in Annex II, only P. bogaraveo is managed by TAC. Additionally, for some specific stock measures such as effort limitation, licensing, capacity limits, technical measures, and spatial and temporal closures are used; vulnerable marine ecosystems (VME) and protected, endangered and threatened species (PET) encounter protocols have been implemented in recent years.

Management strategy evaluation (MSE) or operational management procedure (OMP) (De la Mare 1998; Punt and Donovan 2007; Rademeyer et al. 2007) consists in analysing the performance of management strategies by simulation before their implementation. In the analysis, the main sources of uncertainty in the knowledge of fishery systems, including the management process should be taken into account in order to find management strategies robust to these uncertainties. Thus, this approach is relevant to the management of data-poor stock characterized by a large uncertainty. In this study, we used FLBEIA (Bio-economic impact assessment using FLR, Jardim et al. 2013) to analyse management strategies for three deepwater case studies: Sebastes mentella (beaked redfish) in ICES Subareas I and II, Pagellus bogaraveo (blackspot seabream) in the Strait of Gibraltar and French mixed deepwater fisheries in the NE Atlantic. FLBEIA is a modelling toolbox that allows evaluation of the biological and economic performance of management strategies in a mixed fisheries context using an MSE approach. Its structure is similar to that of the BIOMAS model (Ives and Scandol 2013), but FLBEIA is focused on the European way of assessing and managing stocks. A conceptual diagram of the model is shown in Figure 1. It is divided into two components: the operating model (OM) and the management procedure model (MPM). The first describes the real system and is composed of the stock, fleets and OM covariates. MPM represents the management process and it is composed

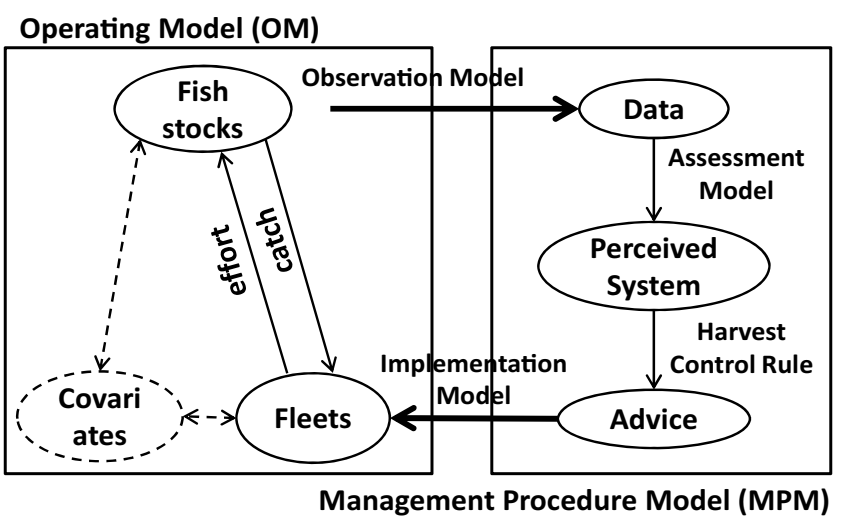

Fig. 1. Conceptual representation of the main components modelled in FLBEIA.

of the data collection, assessment procedure and management advice.

This study is part of the European Union (EU) project DEEPFISHMAN (2012), whose aim was to develop a shortand long-term monitoring and management framework for deepwater fisheries in the NE Atlantic. The case studies presented here were selected to test some of the management procedures proposed by the project. The case studies include different problems common to fishery systems in general and to deepwater systems in particular.

The Sebastes mentella fishery operates in national and international waters and each area has its own management. In international waters, a TAC is established by consensus by the North-East Atlantic Fisheries Commission (NEAFC), while in national waters, the fishery is mainly bycatch, which has its own specific regulations. Nevertheless, total catch in both these waters cannot exceed the level recommended by ICES based on the maximum sustainable yield (MSY) approach. Therefore, the divided management combined with the biological and behavioural uncertainties of the stock (Roques et al. 2002; Stransky 2005) makes it difficult to exploit the stock sustainably.

Pagellus bogaraveo in the Strait of Gibraltar is a data-poor stock harvested by a local artisanal fishery (Gil 2006). Since 2003, a biannual TAC has been applied to P. bogaraveo, which has always been far below the landings reported. In the period 2003-2010, some technical measures were implemented by the Regional Government of Andalucía that included a more restrictive TAC $(270 \mathrm{t})$ than in EU regulation. However, the suitability of this alternative TAC has never been evaluated.

The French mixed deepwater fisheries case study was done on several stocks. However, these stocks are each managed on a single stock basis, so their management may not be congruent. Nowadays, in the light of ecosystem based fisheries management (Pikitch et al. 2004; Curtin and Prellezo 2010), there is a need to change from the single stock management approach to more holistic management. In this sense, managing fisheries in a mixed fisheries context represents a step in the right direction. Modelling mixed fisheries is challenging because there is a lack of established models to describe their dynamics. In the area of this case study, significant advances were recently made in describing fleet dynamics 
(Marchal et al. 2013, Marchal and Vermard 2013). In the present paper, we use the data used in these earlier studies to condition the simulation model.

Thus, these stocks could be being managed in a manner that is either too risky, meaning that stock sustainability could be compromised, or too conservative, meaning that fishers could be losing fishing opportunities. We evaluated the performance of three harvest control rules (HCRs):

- A constant total allowable catch (TAC) strategy.

- The HCR proposed by ICES in the MSY framework.

- The HCR proposed by European Commission in the framework of data-poor stocks.

Different scenarios were run that differed in the stock and fleet dynamics used to describe the real system and in the strategies used to manage them. The objective of this paper was to test the performance of the HCRs in the context of three deepwater stock case studies:

- In the Sebastes mentella case study, the relationship between sustainability and different stock recruitment was tested.

- In the Pagellus bogaraveo case study, special attention was given to uncertainty parameterization.

- In the French mixed deepwater case study, different fleet dynamics were considered.

\section{Materials and methods}

\subsection{Management strategy evaluation}

Simulation in a MSE approach is divided into two submodels: the operating model (OM), which simulates the real fishery system, and the MPM, which simulates the management process. The aim of this approach is to evaluate the robustness of the management strategies with regard to the uncertainties in the fishery system, including the management process. When a management strategy is tested using this approach, the management advice is not given based on the population simulated in the OM (the real population), but on the population estimated by the assessment model in the MPM (the perceived population). Thus, in addition to the strategy, its performance in combination with the data collection and the assessment model is also evaluated.

\subsection{FLBEIA model}

FLBEIA (Jardim et al. 2013) is a simulation model developed in R (R Development Core Team 2011) using FLR libraries (Kell et al. 2007). The model follows the MSE approach; hence, it is divided into two large blocks, the OM and the MPM. A conceptual diagram of the model is shown in Figure 1. In FLBEIA, the OM is formed by fish stocks, fleets and covariates, and the MPM is formed by the observation, assessment and management advice models. The stocks can be agestructured or aggregated in biomass and there are no trophic interactions. Fleet activity is divided into metiers ${ }^{2}$ and their

\footnotetext{
${ }^{2}$ Metiers are defined as trips within a fleet that share the same characteristics in terms of gear used, fishing area and catch profiles (Marchal 2008).
}

projection is divided into four parts: effort allocation, catch production, stock price dynamics and capital dynamics. Effort allocation determines how much effort is exerted and how this is allocated among metiers within a fleet; catch production describes the relationship between effort and catch. In this study three effort allocation models were used:

- Status quo: The effort and its allocation along metiers were set equal to the average of the last three data years (20062008).

- Fcube-like approach (Fcube): Total effort is calculated based on the TAC advice of the stocks caught by the fleet and their allocation along metiers is given as input data. The effort associated to the TAC of each of the stocks caught by the fleet is calculated, and the effort of one of the stocks then is selected to forecast fleet's effort. In this case, effort allocation for metiers was set equal to the average of the last three historical years. This approach is based on the Fcube method presented in Ulrich et al. (2011) and Iriondo et al. (2012).

- Maximum conditional profit (MCP) calculates the total effort and the effort share along metiers that maximizes the profits, a common approach used to model fisher behaviour (van Putten et al. 2012). In this study, the effort is constrained by the capacity of the fleet (measured in the same units as effort) and by the catch of a selected stock.

Maximum conditional profit runs annually in the last season. Despite the OM seasonal dimension, all the simulated data is generated annually. The observation model simulates two kinds of data: (i) data related to fleet production (landing and discard data), data related to biology of the stock (natural mortality, fecundity and individual weight) and stock status indicators (stock abundance and exploitation rate), (ii) abundance indices that it simulates using a linear or a power relationship between the abundance and the index. In reality, stock status indicators are not observable variables; however, in simulation studies, it is useful to observe them and apply the HCR directly to evaluate its performance alone.

Assessment models are applied independently, stock by stock. They calculate estimates of stock abundance and/or exploitation rate and returns estimates of the real populations simulated in the operating model. In this study, extended survivor analysis (XSA, Shepherd 1999) was used in some of the simulation scenarios for P. bogaraveo and Molva dypterygia stocks. When XSA was not used within the MPM, it was assumed that the stock status, exploitation rate and abundance were known to be without errors. Otherwise the advice was given based on an abundance index generated by the observation model.

Management advice is generated by means of the HCR. In this paper we analyse three HCRs: constant TAC, ICES MSY framework (ICES HCR) and Annex IV HCR:

ICES HCR's objective of this model is to maintain fishing mortality at $F_{m s y}$ (usually an MSY proxy).This HCR (Fig. 2) can be found in the WKFRAME report (ICES 2012). The corresponding fishing mortality is transformed into catch in order to obtain the TAC advice. ICES has not defined an $F_{\text {target }}$ when $S S B>B_{\text {lim }}$. Below this point, it is supposed that the 


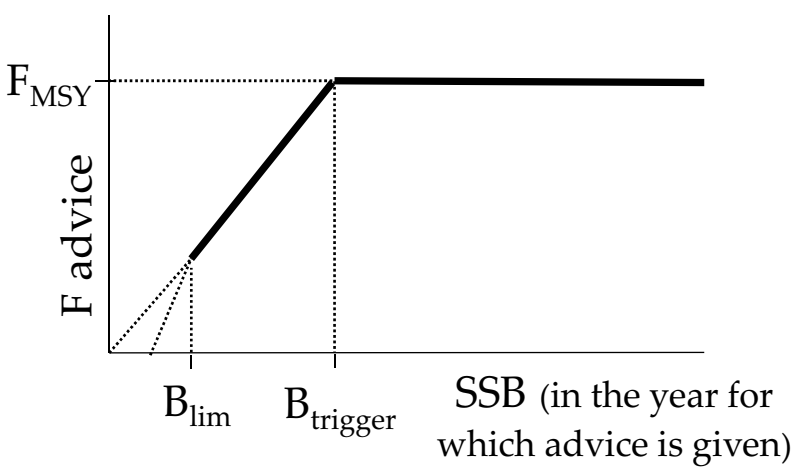

Fig. 2. Graphical representation of HCR corresponding to ICES MSY framework, adapted from WKFRAME report ICES (2010).

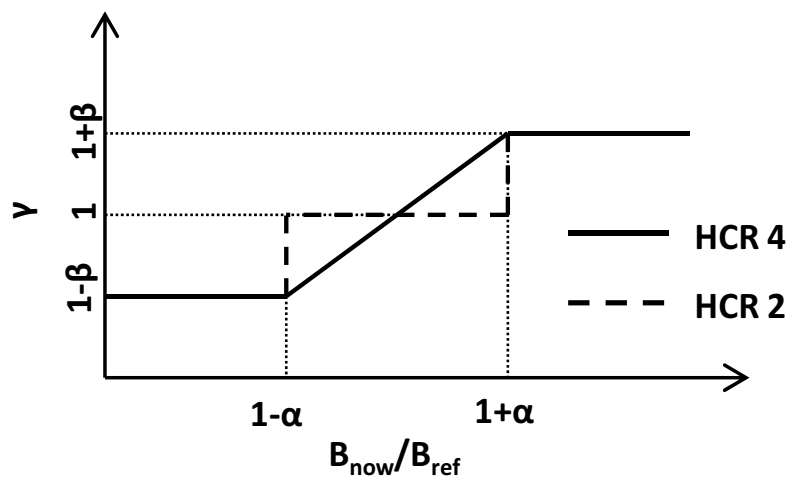

Fig. 3. Graphical representation of Annex IV HCR, where, $B_{\text {now }}=$ $\frac{B_{y}+B_{y-1}}{2}, B_{\text {ref }}=\frac{B_{y-2}+B_{y-3}+B_{y-4}}{3}$ and $B$ denotes de index value (from ICES 2010).

risk of collapse is high, thus $F_{\text {target }}$ should be restrictive. Here, $F_{\text {target }}=0$ was chosen for this range of SSB.

When biological reference points were not available, a reasonable $B_{\text {lim }}$ was first selected and $B_{\text {trigger }}$ was defined as $1.4 B_{\text {lim }}$, a common approach used in the ICES precautionary approach framework to define a precautionary approach biomass ( $B_{P A}$, Hauge et al. 2007). In age-structured populations, $F_{0.1}{ }^{3}$ was used as an $F_{m s y}$ proxy to avoid relying on the stock-recruitment relationship; in biomass dynamic ones, $F_{m s y}$ itself was used. $F_{0.1}$ was proposed within the project (DEEPFISHMAN, 2012) as an appropriate fishing mortality target to manage deepwater stocks.

Annex IV HCR uses an abundance index to give TAC advice. The most recent index points are compared with previous ones and TAC is changed depending on the difference (in percentage) with the previous year. This HCR was defined by the EC and was tested by simulation (ICES 2010). Figure 3 shows a graphical representation of the rule. There are two different versions which depend on the advice given when the ratio between current index and reference index is in the range $(1-\alpha$, $1+\alpha$ ). Here, $\alpha$ and $\beta$ were set equal to the default values 0.20 and 0.15 , respectively.

${ }^{3}$ Fishing mortality rate where the slope of the yield per recruit rate curve is $10 \%$ of the maximum slope (Quinn and Deriso 1999).

\subsection{Sebastes mentella}

S. mentella was traditionally caught in a demersal fishery conducted by Russia and other East European countries but, since 2004 , the only directed fisheries for $S$. mentella are by pelagic trawls in the Norwegian Sea. The fishery is managed by the North-East Atlantic Fisheries Commission, and a TAC of $7500 \mathrm{t}$ was decided by consensus for 2012. However, there are other fisheries targeting other species (e.g. shrimp) that have an allowed maximum bycatch of $S$. mentella but which are not included in this study.

In the assessment, a statistical catch at age (1992-2011) model and Gadget and Schaefer biomass models were used (ICES 2012). The data used in this case study were explained in detail by ICES (2012). There was no data on discards, effort or economics.

\section{Biological operating model}

To initialize the model, a historical random population with 100 iterations was created from the joint probability distribution of the Bayesian statistical catch at age (SCAA) assessment model (Planque et al. 2011) used in the evaluation of the stock.

Historical data does not show any clear relationship between stock and recruitment for S. mentella (ICES 2012), therefore, two different methods were used to make a sensitivity analysis and compare the simulations:

- Segmented regression: the parameters were estimated by fitting the model with historical data of $S S B$ and recruitment for each of the iterations.

- An autoregressive recruitment model, where the recruitment depends on the previous year with normally distributed uncertainty (ARR). At $S S B$ values lower than $\alpha$, recruitment estimates decrease with $S S B$ :

$$
\text { rect }=\left\{\begin{array}{c}
(\text { rect }-1+R) \times \frac{s s b}{\alpha} s s b<\alpha \\
\operatorname{rect}-1+R \quad s s b<\alpha
\end{array}\right.
$$

where $R$ : $N\left(0, \sigma^{2}\right)$ and $\min _{R}<R<\max _{R}$.

We set $\alpha=20000 \mathrm{t}$, as a value close to the historical minimum data of $S S B$. We estimated $\sigma$ as the variability of the differences in recruitment between years. The maximum $\max _{R}$ $(622964 \mathrm{t})$ and minimum $\min _{R}(20378 \mathrm{t})$ recruitment were calculated from the data.

Biological parameters such as maturity-, weight- and natural mortality-at-age were conditioned using the average of last three historical values.

\section{Fleet operating model}

In this study, data of fisheries with targets other than S. mentella were not available and demersal fisheries have almost disappeared; therefore, for simplicity, the two fisheries datasets were treated as one. So the analysis of this case study was reduced to a single fleet and single stock.

The catch production was simulated using a Cobb-Douglas production model (Cobb and Douglas 1928). The parameters of the production function were obtained by fitting a linear model to the logarithms of historic abundance at age and historic effort. The parameters obtained were used to produce the catch in the projection. 


\section{Management procedure model}

In the observation model it was assumed that the stock status (numbers and fishing mortality-at-age) was known without error. Thus, we did not consider any assessment. The management advice was generated using two different HCR, a constant TAC HCR (8000 t, the average of the last three years), and ICES HCR. In ICES HCR $F_{\text {target }}$ was set equal to $F_{0.1}=0.065$ (close to the natural mortality, 0.05) (ICES, 2012). Annex (Table S1) summarizes the scenarios simulated in this case study.

\subsection{Pagellus bogaraveo}

$P$. bogaraveo of gulf of Cadiz is a deepwater stock exploited by an artisanal fleet. The fleet is made up of longliners that target $P$. bogaraveo on most of their trips and only catch $P$. bogaraveo in these trips. The vessels involved in the fishery form a homogeneous group in terms of technical characteristics. The extended survivors analysis (XSA) (Shepherd 1999 ) is routinely applied in the assessment working group; however, due to the uncertainty in the abundance index and low stability of the fit, the assessment is not approved and not used to inform management agencies. Since 2003, the stock has been managed with a constant TAC (270 t), although the fleet usually exceeds by more than twice. More information about the biology, assessment and management of the stock can be found in Gil (2006). The data was obtained from the assessment working group (ICES 2012) and from Gil (2006) and the model was conditioned as single stock and single fleet.

\section{Biological operating model}

To initialize the model a historical random population with 500 iterations was created. Randomness was generated modelling two important sources of uncertainty:

- Abundance index used to tune the XSA. It was not possible to quantify its uncertainty in a reliable way; therefore, it was assumed that its variability followed a lognormal distribution with a coefficient of variation $(\mathrm{CV})$ of $30 \%$.

- Individual growth in length. A Bayesian Von Bertalanffy growth model was fit to age-length data and the joint probability distribution was used to build a set of random agelength keys (see Appendix A for a detailed description of the procedure). These keys were applied to length distributions of catch, weight and abundance indices to obtain random variables-at-age.

XSA was applied to these random variables and abundance indices and thus historic random numbers- and fishing mortalityat-age were obtained. Stock dynamics in the simulation were described using an exponential survival model combined with a segmented regression stock-recruitment relationship. The parameters of the stock-recruitment relationship were obtained by fitting the model to each of the iterations to the historical population. Furthermore within the simulation a lognormal random error $(\mu=0$ and variance equal to the variance of the residuals in the model fit) was multiplied to the recruitment point estimates. Biological parameters such as maturity-, weight- and natural mortality-at-age were conditioned using the average of the last three historical values.

\section{Fleet operating model}

The catch production was simulated using a Cobb-Douglas production model (Cobb and Douglas 1928). The parameters of the production function were obtained by fitting a linear model to the logarithms of historic abundance-at-age and historic effort. The parameters obtained were used to produce the catch in the projection. This fishery systematically overshoots the TAC; thus, in some scenarios, it was assumed that the fleet overshot it. The overshoot was parameterized stochastically using a triangular distribution (Evans 2000) where distribution parameters corresponded with observed values. Fleet effort corresponded to the effort that produced the $T A C$ or the $T A C$ plus the overshoot.

\section{Management procedure model}

\section{Observation model}

The observed data depended on the assessment model and the HCR used. A list of the options used in each of the 13 scenarios simulated is shown in Table S2. To apply the Annex IV HCR, a linear biomass abundance index was simulated and, in some scenarios, a multiplicative error was introduced. ICES HCR was tested on top of real population and XSA estimates. In the first case stock indicators were taken from the real population and in the second case catch- and linear abundance index-at-age were simulated. The following observation errors were introduced into the scenarios:

- A multinomial random error related to aging error in "at age" data. It represented the probability of assigning age $j$ to an individual with real age $i$. Parameterization was done using Von Bertalanffy growth parameters. The observation error was derived from natural variability in growth and not from bias in age reading or sampling.

- When the TAC was exceeded, no declaration being made of TAC surplus.

- A lognormal random error with $30 \%$ of CV and median equal one multiplied to the index.

\section{Assessment model}

In four of the scenarios, XSA was applied to observed data with different observation errors and ICES HCR was applied to the estimates obtained. In the rest of the scenarios where ICES HCR was used, stock abundance and fishing mortality were taken directly from the simulated real population in the OM.

\section{Management advice}

The management advice was generated using three different HCR: a constant TAC HCR, Annex IV HCR and ICES HCR. In ICES HCR, $B_{\text {lim }}$ was defined as $B_{\text {loss }}(=550 \mathrm{t})$ and the $F_{\text {target }}$ was set as equal to the median of $F_{0.1}$ in the historical random population $(0.11)$.

\subsection{French mixed deepwater fishery}

The demersal mixed deepwater fishery in NE Atlantic is mainly made up of French deepwater trawlers. In this study, 
we considered the same case study as in Marchal et al. (2013) and we used the same basic data to condition the model. We considered five stocks: Molva dypterygia (blue ling), Coryphaenoides rupestris (roundnose grenadier), Aphanopus carbo (black scabbardfish) and a mix of deepwater sharks; and seven fleets. Two of the fleets were defined as the French ones in Marchal et al. (2013). The other five fleets were 'artificial' single stock fleets, which account for the international catch not taken by the French fleets. A detailed description of the stocks and the fleets can be found in Marchal et al. (2013).

\section{Biological operating model}

$M$. dypterygia and $P$. virens were simulated as age structured populations and A. carbo, C. rupestris and the sharks as biomass dynamic populations.

Historic random populations were constructed, adjusting assessment models to historic data. For $P$. virens and $M$. dypterygia XSA was adjusted to catch-at-age matrices and random abundance indices. $P$. virens is already managed using XSA and the model configuration used in the assessment working group was used (ICES 2012). For M. dypterygia, the model configuration proposed in Marchal et al. (2013) was used. In both cases, random historic abundance indices were constructed doing a parametric bootstrap of the catchability residuals of an initial XSA fit to the observed data. Biomass dynamic historic populations were obtained fitting a Schaefer production model to the observed data. For $C$. rupestris, the Bayesian model used to assess the stock was applied (ICES 2012). A. carbo and sharks do not have any approved assessment, so the deterministic model described in Marchal et al. (2013) was used.

In the projection, age-structured populations were carried forward using an exponential survival model together with a stock recruitment relationship. Biological parameters such as maturity-, weight- and natural mortality-at-age were conditioned using the average of last three historical values. For these two stocks, recruitment was simulated using a segmented regression model parameterized as in the case of $P$. bogaraveo. Biomass dynamic populations were projected using the Schaefer production model with the parameters estimated in the historical period. A. carbo and shark population growth parameters were the same for all the iterations. In the case of $C$. rupestris, each iteration had a different set of parameters sampled from the joint probability distribution obtained in the Bayesian fit.

\section{Fleet operating model}

The OM fleet was composed of seven fleets: the French fleets, FL01 and FL02, and the five "artificial" fleets, FLBLI, FLBSF, FLRNG, FLPOK and FLSKH. Activity of FL01 and FL02 was divided into 10 metiers. The metiers differed in stock catchability. Stock price and weight and fleet (FL01) variable costs were common to all the metiers. Economic data was only available for FL01. FL01 accounted for most of the French catch $(\sim 80 \%)$ and FL02 for the rest.

The FL01 dynamic was simulated using the three effort allocation models described in previous sections, for the rest, only the first two were used because economic data was not available. In the Fcube model, the fleets that did not catch the stock that restrained the effort stopped fishing when the quota was exhausted (this only occurred for single stock fleets). For all the fleets, catch production was simulated using a CobbDouglas production model (Cobb and Douglas 1928). The parameters of the production function were obtained by fitting a linear model to the logarithms of historic abundances and effort. For age-structured stocks, the parameters were fitted at age level and for the rest of the populations, at total biomass level. The parameters obtained were used to produce the catch in the projection.

\section{Management procedure model}

\section{Observation model}

The observation model for each of the stocks depended on the HCR and the assessment model used in each of the scenarios. For sharks, an observation model was not necessary because it was managed with a constant TAC rule. When Annex IV HCR was used for any of the stock, an abundance index was generated for the stock itself, with a median equal to one and $30 \%$ of the CV. In one of the scenarios, XSA was used for $M$. dypterygia to estimate stock abundance and fishing mortality. In this case, a catch-at-age matrix, without observation error, and a linear abundance index with a multiplicative lognormal error (median equal one and $30 \%$ of the $\mathrm{CV}$ ) were created. The other stocks were observed without error, i.e., stock abundance and exploitation rate were taken directly and without error from the real population.

\section{Assessment model}

An assessment model within the management procedure model (MPM) was only used for M. dypterygia, for which XSA was used with the same configuration as that used in the historic fit.

\section{Management advice}

Different HCRs were used to produce the TAC advice for each of the stocks. Annex IV and ICES HCR were tested in $M$. dypterygia, A. carbo and C. rupestris stocks and constant TAC with different catch levels was tested for sharks. Total allowable landing (TAL) advice is 0 for sharks, i.e., landings are not allowed, but discards are not banned. TAC $=0$ (no landings, no discards) was not tested because, under the current model configuration, shark catchability is greater than zero in all their metiers, so this would imply closing FL01 and FL02 fleets. $P$. virens was not of primary interest in this study and only the HCR used in its management plan was tested (ICES 2011).

Fishing mortality reference points the within ICES HCR were calculated using yield per recruit analysis, and biomass reference points were chosen based on historic evolution of the stocks. For $P$. virens, the reference points were taken from its management plan (ICES 2011). For $M$. dypterygia, $B_{\text {lim }}$ was defined as $B_{\text {loss }}\left(17850 \mathrm{t}\right.$ and $\left.F_{0.1}=0.18\right)$. For $A$. carbo, $B_{\text {loss }}>B_{m s y}$, and to be precautious, we defined $B_{\text {lim }}=0.5 B_{m s y}$, $\left(B_{\text {lim }}=15160 \mathrm{t}\right), F_{m s y}=0.21$. For $C$. rupestris, $B_{\text {loss }}=B_{m s y}$ 


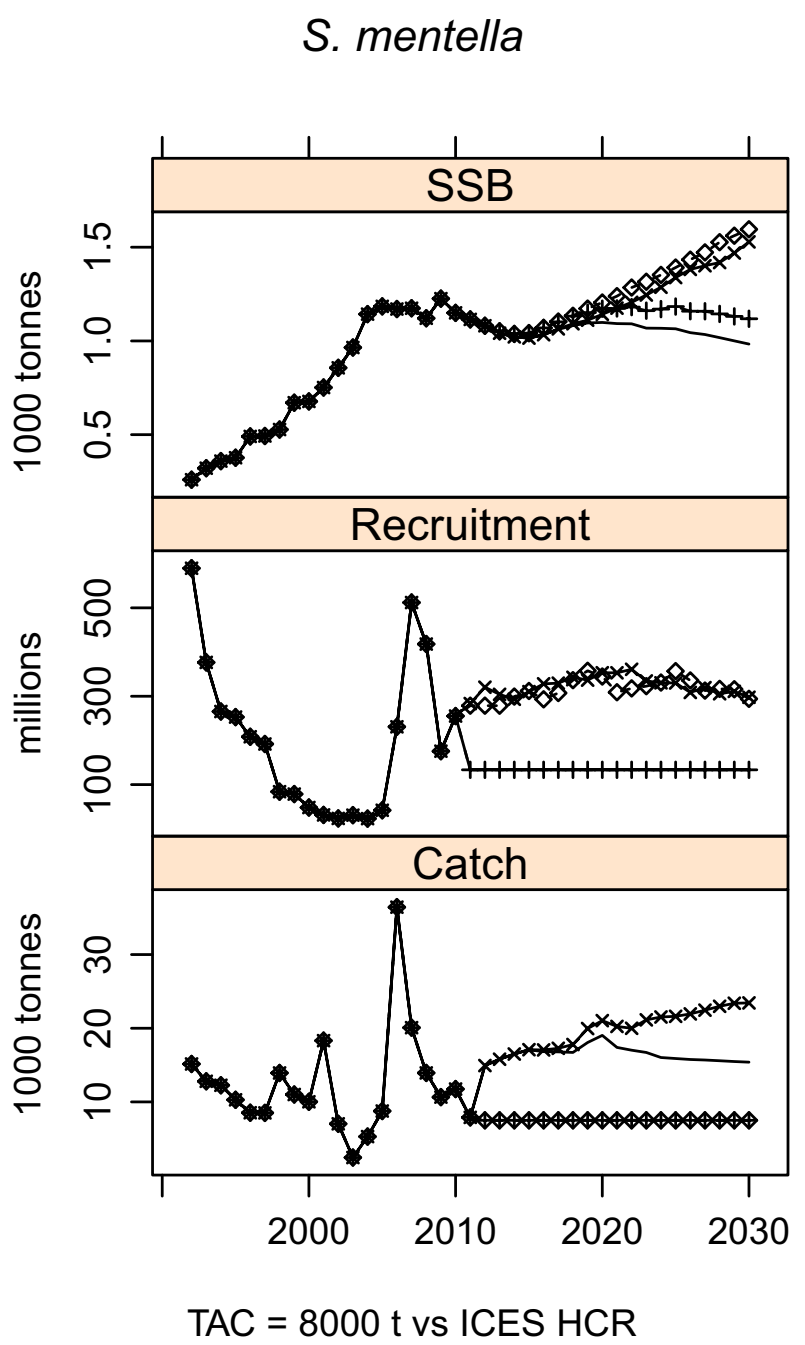

Fig. 4. Historical data and projection of Sebastes mentella spawning stock biomass $(S S B)$, recruitment and catch under different stock recruitment models and advice. Solid lines correspond to the scenario where segmented regression was used as the stock recruitment relationship and advice was based on ICES HCR; plus sign to segmented regression and fixed $T A C$; diamonds to stock recruitment relationship based on the previous year's recruitment; crosses to stock recruitment based on the previous year's recruitment and fixed TAC.

and we follow the same approach as for $A$. carbo $\left(B_{\text {lim }}=\right.$ $33575 \mathrm{t}), F_{m s y}=0.08$.

Thirteen scenarios were run that depended on fleet dynamics and management procedure. Table $\mathrm{S} 3$ gives a brief description of the options used in each scenario.

\section{Results}

\subsection{Sebastes mentella}

Projection of S. mentella under different stock recruitment relationships showed that the results were sensitive to the method chosen (Fig. 4). Even if the differences in recruitment between the methods were constant with time, these differences were accumulated in the SSB estimates and became larger with time due to the long life history of $S$. mentella.

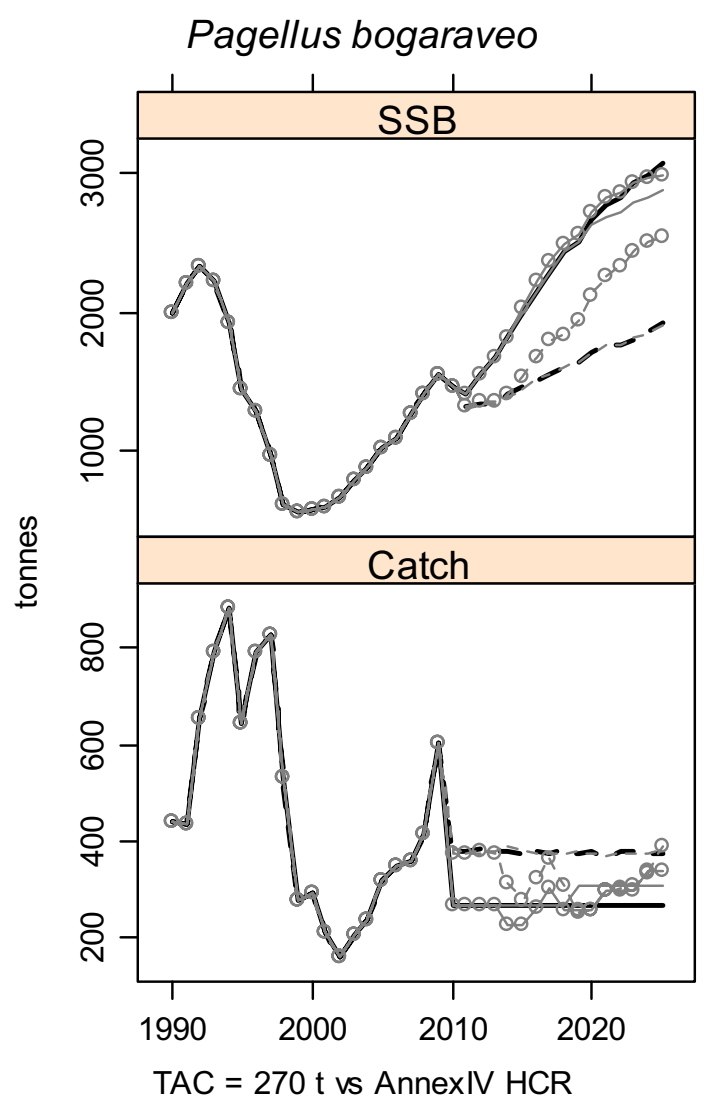

Fig. 5. Pagellus bogaraveo spawning stock biomass (SSB) and catch time series in current management and Annex IV HCR (see Table S3) scenarios. Black lines correspond to current management and grey ones to Annex IV HCR scenarios. Solid lines represent scenarios where the TAC was implemented correctly and dashed ones scenarios with $T A C$ overshooting. Dotted lines indicate that observation error was introduced into the abundance index.

Both stock recruitment methods suggested that the advice of the last three years average $T A C$, as well as the $F_{m s y}$ advised by ICES, is sustainable.

The probability of $S S B<B_{\text {lim }}$, and the probability of $S S B<B_{\text {trigger }}$ were 0 for all the scenarios. The probability of fishing mortality $>F_{m s y}$ was also 0 for all the scenarios.

\subsection{Pagellus bogaraveo}

The recruitment was the same for all the scenarios, meaning that $S S B$ did not fall below the breakpoint in the segmented regression stock-recruitment relationship for any of the scenarios.

The $S S B$ had a similar increasing trend in the two scenarios where TAC was constant, but the increase level was very different (Figs. 5 and 6). In the scenario with correct implementation of the advice, the SSB exceeded historical ones, while in the scenario with implementation error, it remained below those levels. The catch was $40 \%$ higher when the implementation error was included.

Current management and Annex IV HCR gave the same results when implementation error was introduced and there was 


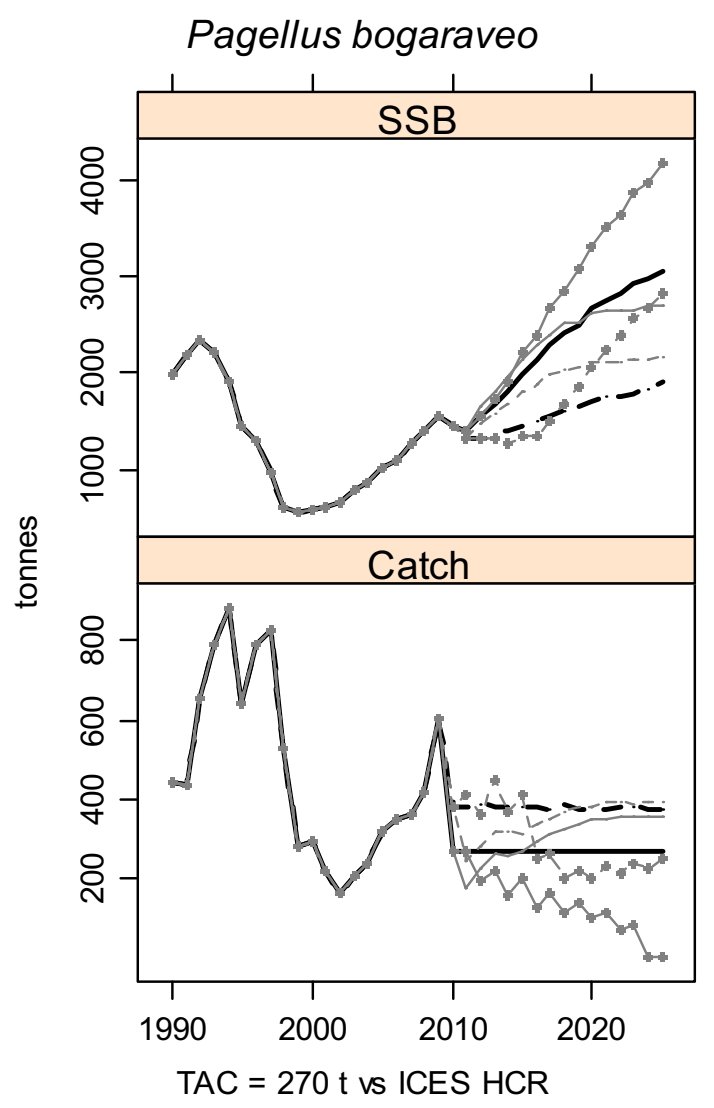

Fig. 6. Pagellus bogaraveo spawning stock biomass (SSB) and catch time series in current management and ICES HCR (see Table S3) scenarios. Black lines correspond to current management and grey ones to Annex IV HCR (see Table S3) scenarios. Solid lines represent scenarios where the $T A C$ was implemented correctly and dashed ones scenarios with TAC overshooting. Lines with filled points correspond to scenarios where XSA was used; the rest of the lines belong to scenarios where the perceived population was taken directly from the operating model $(\mathrm{OM})$. The line with empty triangles corresponds to the scenario where aging error was introduced into the perceived population. Filled triangles correspond to the scenario with aging error and overshooting reported. The rest of filled points correspond to scenarios where, if overshooting occurred, it was not reported. Diamonds represent the scenario with undeclared overshooting and aging error.

no observation error (Fig. 5). When Annex IV HCR was used, the increase in $S S B$ was not sufficiently pronounced to cause an increase in the $T A C$, and hence the catch was unchanged in the whole projection. The scenarios where the implementation was considered correct gave similar results. With Annex IV $\mathrm{HCR}$, the catch fluctuated around $270 \mathrm{t}$ and finished the simulation slightly above. The indicators in the scenarios with implementation and observation error and Annex IV HCR were between the indicators in the other two groups.

Two groups were clearly differentiated when ICES HCR was used (Fig. 6): one group consisted of the scenarios where XSA was used to obtain a perceived population, and the other group consisted of the scenarios where the perceived population was directly taken from the real population.

When the population was observed directly, the effect of implementation and aging errors were analysed in separate scenarios. In both cases, the results were parallel to the case where no observation error was included and the management was successful. When implementation error was included, the $S S B$ was significantly lower. However, aging error did not make great differences to the results. XSA was used in four scenarios. The management failed in all the scenarios except when implementation error was observed. Although the population was healthy, the XSA estimated an overexploited population with very high fishing mortality and low SSB. Annually, a reduction in catch was recommended and, in the last years, the advice was zero catch and the SSB doubled the historical maximum. When implementation error was observed, the management was successful in most of the iterations. The median fishing mortality remained above the target for some years, but then started to decrease and ended the simulation slightly below the target. The median of the catch was slightly below $270 \mathrm{t}$ in the whole projection. The SSB started increasing when fishing mortality decreased and was finally close to the scenario with constant TAC and correct implementation. However, the management failed in some iterations as happened in the rest of the scenarios where XSA was used.

The probability of $S S B<B_{\text {lim }}$ was lower than $5 \%$ in all the scenarios; furthermore, it was equal to 0 in most of the cases. The probability of $S S B<B_{\text {trigger }}$ was slightly above $5 \%$ for a few years, but only in the scenario where XSA was used together with aging and observed implementation error. In the rest of the scenarios and years, the probability was below $5 \%$ and in most of the cases it was equal to 0 . The probability of fishing mortality $>F_{m s y}=100 \%$ at the start of the simulation. When implementation error was considered and XSA was not used, the probability of being above $F_{m s y}$ was close to $100 \%$; in the rest of the scenarios, this probability decreased with years and, at the end of the simulation, was lower than $20 \%$.

\subsection{French mixed deepwater fishery}

\subsubsection{Probability of SSB $<\mathrm{B}_{\lim }$}

The probability ( $p$ ) of $S S B<B_{\text {lim }}$ is shown in Table 1 . This probability was always 0 for $A$. carbo, $P$. virens and the sharks. At the start of the simulation, $p=0$ for $M$. dypterygia in all the scenarios where MCP was applied (mf2, mf6, $\mathrm{mf} 7, \mathrm{mf} 8$ ), independently of the restrictor and the level of the shark TAC. In the Fcube scenario, with $M$. dypterygia as restrictor, $p$ increased slightly in the short term but decreased to 0 in the medium term. In the rest of the scenarios, $p$ increased year by year. In the scenario where XSA was applied to $M$. dypterygia $(\mathrm{mf} 3)$ and in the scenario with $C$. rupestris as restrictor using ICES HCR ( $\mathrm{mf} 11)$, the increase was moderate and $p$ reached $23 \%$ and $8 \%$, respectively, in the long term. However, $p$ was close to $80 \%$ in the status quo scenario, the scenarios with Annex IV HCR applied to M. dypterygia and C. rupestris ( $\mathrm{mf} 4$ and $\mathrm{mf} 12$ ) and the scenario with ICES HCR applied to $A$. carbo (mf9).

In the case of $C$. rupestris, in $2009, p=50 \%$. In the medium or long term, it only decreased below $5 \%$ in the scenarios where profits where maximized $(\mathrm{mf} 2, \mathrm{mf} 6, \mathrm{mf} 7$ and mf8) When Fcube was used with sharks as restrictors (mf5), in the scenario with A. carbo as restrictor combined with Annex IV HCR (mf10) and in the scenario with $C$. rupestris as 
Table 1. Probability of the spawning stock biomass $S S B<B_{\text {lim }}$ in 2009, and the average of this probability in the periods 2010-2014, 2015-2019 and 2020-2025. MCP: maximum conditional profit, XSA: extended survivors analysis, TAC: total allowable catch.

\begin{tabular}{|c|c|c|c|c|c|c|c|}
\hline Stock & Scenario & Descr & iption & 2009 & 2010-2014 & 2015-2019 & 2020-2025 \\
\hline \multirow{10}{*}{ 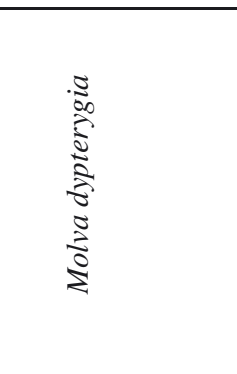 } & mf0 & Status quo effort & & 0 & 0.15 & 0.55 & 0.77 \\
\hline & $\mathrm{mf} 1$ & \multirow{4}{*}{ M. dypterygia restriction } & Fcube + ICES & 0 & 0.01 & 0 & 0 \\
\hline & $\mathrm{mf} 2$ & & $\mathrm{MCP}+\mathrm{ICES}$ & & & 0 & \\
\hline & $\mathrm{mf} 3$ & & Fcube + XSA + ICES & 0 & 0.03 & 0.15 & 0.23 \\
\hline & $\mathrm{mf} 4$ & & Fcube + Annex IV & 0 & 0.34 & 0.76 & 0.83 \\
\hline & $\mathrm{mf} 5, \ldots, \mathrm{mf} 8$ & Shark restriction & all scenarios & & & 0 & \\
\hline & mf9 & \multirow{2}{*}{ A. carbo restriction } & Fcube + ICES & 0 & 0.14 & 0.66 & 0.85 \\
\hline & $\operatorname{mf} 10$ & & Fcube + Annex IV & & & 0 & \\
\hline & mf11 & \multirow{2}{*}{ C. rupestris restriction } & Fcube + ICES & 0 & 0.03 & 0.05 & 0.08 \\
\hline & $\mathrm{mf} 12$ & & Fcube + Annex IV & 0 & 0.31 & 0.77 & 0.78 \\
\hline \multirow{13}{*}{ 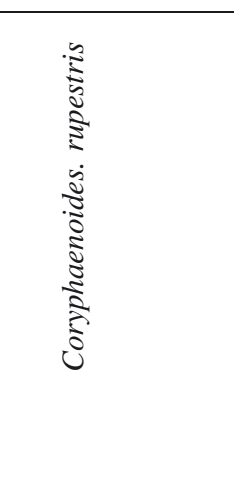 } & $\mathrm{mfO}$ & \multicolumn{2}{|c|}{ Statu quo effort } & 0.50 & 0.51 & 0.52 & 0.51 \\
\hline & $\mathrm{mf} 1$ & \multirow{4}{*}{ M. dypterygia restriction } & Fcube + ICES & 0.50 & 0.43 & 0.28 & 0.18 \\
\hline & $\mathrm{mf} 2$ & & MCP + ICES & 0.50 & 0.33 & 0.07 & 0.01 \\
\hline & $\mathrm{mf} 3$ & & Fcube + XSA + ICES & 0.50 & 0.45 & 0.39 & 0.32 \\
\hline & $\mathrm{mf} 4$ & & Fcube + Annex IV & 0.50 & 0.56 & 0.64 & 0.70 \\
\hline & $\mathrm{mf5}$ & \multirow{4}{*}{ Shark restriction } & Fcube $+T A C_{\mathrm{SKH}}=500 \mathrm{t}$ & 0.50 & 0.34 & 0.08 & 0.01 \\
\hline & mf6 & & $\mathrm{MCP}+T A C_{\mathrm{SKH}}=500 \mathrm{t}$ & 0.50 & 0.28 & 0.03 & 0 \\
\hline & $\mathrm{mf} 7$ & & $\mathrm{MCP}+T A C_{\mathrm{SKH}}=1500 \mathrm{t}$ & 0.50 & 0.28 & 0.03 & 0 \\
\hline & $\mathrm{mf} 8$ & & $\mathrm{MCP}+T A C_{\mathrm{SKH}}=2500 \mathrm{t}$ & 0.50 & 0.29 & 0.03 & 0 \\
\hline & $\mathrm{mf9}$ & \multirow[b]{2}{*}{ A. carbo restriction } & Fcube + ICES & 0.50 & 0.53 & 0.72 & 0.77 \\
\hline & $\mathrm{mf} 10$ & & Fcube + Annex IV & 0.50 & 0.31 & 0.06 & 0.00 \\
\hline & $\mathrm{mf} 11$ & \multirow{2}{*}{ C. rupestris restriction } & Fcube + ICES & 0.50 & 0.41 & 0.08 & 0 \\
\hline & $\mathrm{mf} 12$ & & Fcube + Annex IV & 0.50 & 0.64 & 0.77 & 0.82 \\
\hline Sharks & All & \multicolumn{2}{|r|}{ E } & \multicolumn{4}{|c|}{0} \\
\hline Aphanopus carbo & All & \multicolumn{2}{|c|}{-} & \multicolumn{4}{|c|}{0} \\
\hline Pollachius virens & All & \multicolumn{2}{|c|}{-} & \multicolumn{4}{|c|}{0} \\
\hline
\end{tabular}

restrictor combined with ICES HCR (mf11). In the status quo scenario (mf0), the probability remained slightly above $50 \%$ for the whole period. In the scenarios where Annex IV HCR was applied with $M$. dypterygia or $C$. rupestris as restrictors ( $\mathrm{mf} 4$ and $\mathrm{mf} 12$ ) and in the scenario with A. carbo as restrictor combined with ICES HCR (mf9), the probability increased year by year and ended the simulation above $70 \%$ in the three scenarios. In the other scenarios ( $\mathrm{mf} 1$ and $\mathrm{mf} 3)$, the probability decreased moderately with time and reached $18 \%$ when XSA was not used in the MPM and $32 \%$ when it was.

\subsubsection{Probability of fishing mortality $>F_{\text {target }}$}

The probability ( $p$ ) of fishing mortality $F>F_{\text {target }}$ was always 0 for $A$. carbo, unlike for sharks in which it was close to $100 \%$ in almost all the scenarios ( $F_{\text {target }}$ for sharks was 0$)$, see Table 2. For $M$. dypterygia in 2009, $p=100 \%$ in the status quo scenario ( $\mathrm{mf0}$ ), the scenarios restrained by $M$. dypterygia itself where profits were not maximized ( $\mathrm{mf1}, \mathrm{mf} 3$ and $\mathrm{mf} 4)$ and the scenarios restrained by $C$. rupestris ( $\mathrm{mf} 11$ and $\mathrm{mf12}$ ). In scenarios $\mathrm{mf} 0$ and $\mathrm{mf} 4$ the probability did not decrease with time; in the rest, the decrease varied between $21 \%$ and $74 \%$. In 2009 , in all the scenarios where profits were maximized (mf2, $\mathrm{mf} 6, \mathrm{mf} 7$ and $\mathrm{mf} 8$ ) and in Fcube scenario with sharks as restrictor (mf5), the fishing mortality was above the target, with a $5 \%$ probability, and decreased to 0 for all of them in most of the projection periods.

For Pollachius virens, fishing mortality was always below the target in status quo scenario ( $\mathrm{mfO})$ : in the scenario where profits were maximized and $M$. dypterygia was the restrictor (mf2) and in all the scenarios where sharks were used as restrictors (mf5, $\mathrm{mf} 6, \mathrm{mf} 7$ and $\mathrm{mf} 8)$. In the two scenarios where C. rupestris was the restrictor ( $\mathrm{mf} 11$ and $\mathrm{mf} 12)$ the probability decreased from $53 \%$ to $3 \%$ when ICES HCR was used, but only to $44 \%$ when Annex IV was used. In contrast, when $M$. dypterygia was the restrictor and Annex IV was used (mf4) and when $A$. carbo was the restrictor and ICES HCR was used (mf9), it increased from $3 \%$ and 0 to $43 \%$ and $60 \%$, respectively. In the other scenarios ( $\mathrm{mf} 1$ and $\mathrm{mf} 3$ ) the probability was $6 \%$ or lower over the whole projection period.

Finally, in the case of $C$. rupestris, $p$ was high, $p>82 \%$, and quite stable in the whole period in the status quo scenario (mf0) and in the scenarios where Annex IV HCR was used with $M$. dypterygia and $C$. rupestris stocks as restrictors ( $\mathrm{mf} 4$ and $\mathrm{mf} 12)$. In contrast, $p=0$ in all the scenarios where profits were maximized with sharks as restrictors (mf6, mf7 and mf8). When shark restriction was combined with Fcube (mf5), the probability decreased from $13 \%$ in 2009 to 0 in the rest of the projection period. The probability also showed a decreasing trend in the scenarios where profits were maximized being $M$. dypterygia the restrictor (mf2), when A. carbo was restraining the effort combined with Annex IV HCR (mf10) and when $C$. rupestris was the restrictor and it was managed using ICES HCR (mf11). However, the starting point and the decrease level in the three scenarios were different. In the scenario where XSA was used for M. dypterygia $(\mathrm{mf} 3)$, the probability was low in the whole projection period with a peak in the medium term. Finally, in the scenario where ICES 
Table 2. Probability of fishing mortality being above $F_{\text {target }}$ in 2009, and the average of this probability in the periods 2010-2014, 2015-2019 and 2020-2025.

\begin{tabular}{|c|c|c|c|c|c|c|c|}
\hline Stock & Scenario & \multirow{2}{*}{\multicolumn{2}{|c|}{$\begin{array}{l}\text { Description } \\
\text { Status quo effort } \\
\end{array}$}} & 2009 & 2010-2014 & 2015-2019 & 2020-2025 \\
\hline \multirow{13}{*}{ 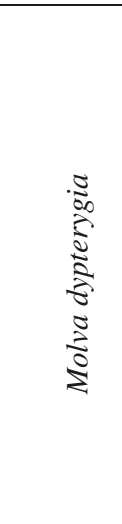 } & $\mathrm{mf0}$ & & & \multicolumn{3}{|c|}{1} & \\
\hline & $\mathrm{mf} 1$ & \multirow{4}{*}{$\begin{array}{l}\text { M. dypterygia } \\
\text { restriction }\end{array}$} & Fcube + ICES & 1 & 0.31 & 0.26 & 0.34 \\
\hline & $\mathrm{mf} 2$ & & MCP + ICES & 0.33 & 0 & 0.01 & 0.03 \\
\hline & $\mathrm{mf} 3$ & & Fcube + XSA + ICES & 1 & 0.66 & 0.85 & 0.65 \\
\hline & $\mathrm{mf} 4$ & & Fcube + Annex IV & & 1 & & \\
\hline & mf5 & \multirow{4}{*}{$\begin{array}{l}\text { Shark } \\
\text { restriction }\end{array}$} & Fcube + ICES & 0.43 & 0 & 0 & 0 \\
\hline & $\operatorname{mf6}$ & & $\mathrm{MCP}+T A C_{\mathrm{SKH}}=500 \mathrm{t}$ & 0.05 & 0 & 0 & 0 \\
\hline & $\mathrm{mf} 7$ & & $\mathrm{MCP}+T A C_{\mathrm{SKH}}=1500 \mathrm{t}$ & 0.05 & 0 & 0 & 0 \\
\hline & mf8 & & $\mathrm{MCP}+T A C_{\mathrm{SKH}}=2500 \mathrm{t}$ & 0.05 & 0 & 0 & 0.01 \\
\hline & mf9 & \multirow{2}{*}{ A. carbo restriction } & Fcube + ICES & 0.22 & 1 & 1 & 1 \\
\hline & $\mathrm{mf} 10$ & & Fcube + Annex IV & 0.22 & 0 & 0 & 0 \\
\hline & $\operatorname{mf} 11$ & \multirow{2}{*}{ C. rupestris restriction } & Fcube + ICES & 1 & 0.31 & 0.28 & 0.21 \\
\hline & $\mathrm{mf} 12$ & & Fcube + Annex IV & 1 & 1 & 0.94 & 0.74 \\
\hline \multirow{10}{*}{ 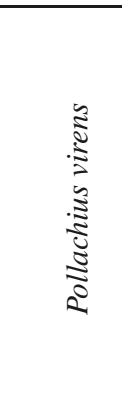 } & \multirow{10}{*}{$\begin{array}{c}\mathrm{mf} 0 \\
\mathrm{mf} 1 \\
\mathrm{mf} 2 \\
\mathrm{mf} 3 \\
\mathrm{mf} 4 \\
\mathrm{mf} 5, \ldots, \mathrm{mf} 8 \\
\mathrm{mf} 9 \\
\mathrm{mf} 10 \\
\mathrm{mf} 11 \\
\mathrm{mf} 12\end{array}$} & \multicolumn{2}{|c|}{ Status quo effort } & & 0 & & \\
\hline & & \multirow{4}{*}{ M. dypterygia restriction } & Fcube + ICES & 0.03 & 0 & 0.01 & 0.01 \\
\hline & & & MCP + ICES & & & 0 & \\
\hline & & & Fcube + XSA + ICES & 0.03 & 0.02 & 0.06 & 0.02 \\
\hline & & & Fcube + Annex IV & 0.03 & 0.31 & 0.42 & 0.43 \\
\hline & & Shark restriction & All scenarios & & & 0 & \\
\hline & & \multirow{2}{*}{ A. carbo restriction } & Fcube + ICES & 0 & 0.57 & 0.60 & 0.60 \\
\hline & & & Fcube + Annex IV & & & 0 & \\
\hline & & \multirow{2}{*}{ C. rupestris restriction } & Fcube + ICES & 0.53 & 0.02 & 0.03 & 0.03 \\
\hline & & & Fcube + Annex IV & 0.53 & 0.53 & 0.57 & 0.44 \\
\hline \multirow{11}{*}{ 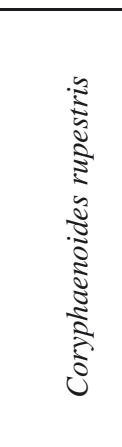 } & \multirow{11}{*}{$\begin{array}{c}\text { mf0 } \\
\text { mf1 } \\
\text { mf2 } \\
\text { mf3 } \\
\text { mf4 } \\
\text { mf5 } \\
\text { mf6, } \mathrm{mf} 7, \mathrm{mf} 8 \\
\text { mf9 } \\
\text { mf10 } \\
\text { mf11 } \\
\text { mf12 }\end{array}$} & \multicolumn{2}{|c|}{ Status quo effort } & 0.85 & 0.83 & 0.82 & 0.82 \\
\hline & & \multirow{4}{*}{ M. dypterygia restriction } & Fcube + ICES & 0.87 & 0.30 & 0.39 & 0.51 \\
\hline & & & MCP + ICES & 0.41 & 0 & 0.01 & 0.06 \\
\hline & & & Fcube + XSA + ICES & 0.87 & 0.46 & 0.70 & 0.50 \\
\hline & & & Fcube + Annex IV & 0.87 & 0.94 & 0.94 & 0.94 \\
\hline & & \multirow{2}{*}{ Shark restriction } & Fcube + ICES & 0.13 & 0 & 0 & 0 \\
\hline & & & $\mathrm{MCP}+$ Any $T A C$ & & 0 & & \\
\hline & & \multirow{2}{*}{ A. carbo restriction } & Fcube + ICES & 0.09 & 0.98 & 0.98 & 0.98 \\
\hline & & & Fcube + Annex IV & 0.09 & 0 & 0 & 0.01 \\
\hline & & \multirow{2}{*}{ C. rupestris restriction } & Fcube + ICES & 0.96 & 0.02 & 0.02 & 0.03 \\
\hline & & & Fcube + Annex IV & 0.96 & 0.97 & 0.99 & 0.99 \\
\hline \multirow{9}{*}{$\begin{array}{l}\frac{y}{\bar{z}} \\
\text { चू }\end{array}$} & \multirow{9}{*}{$\begin{array}{c}\mathrm{mf} 3 \\
\mathrm{mf} 4 \\
\mathrm{mf} 5, \ldots, \mathrm{mf} 8 \\
\mathrm{mf} 9, \mathrm{mf} 10 \\
\mathrm{mf} 11 \\
\mathrm{mf} 12 \\
\end{array}$} & Status & do effort & & 1 & & \\
\hline & & \multirow{4}{*}{ M. dypterygia restriction } & Fcube + ICES & 1 & 0.99 & 1 & 1 \\
\hline & & & $\mathrm{MCP}+\mathrm{ICES}$ & & 1 & & \\
\hline & & & Fcube + XSA + ICES & 1 & 0.97 & 0.96 & 0.84 \\
\hline & & & Fcube + Annex IV & & 1 & & \\
\hline & & Sharks restriction & All scenarios & & 1 & & \\
\hline & & A. carbo restriction & All scenarios & & 1 & & \\
\hline & & & Fcube +ICES & 1 & 0.50 & 0.82 & 0.99 \\
\hline & & C. rupestris restriction & Fcube + Annex IV & & & 1 & \\
\hline A. carbo & All & & & & & 0 & \\
\hline
\end{tabular}

HCR was applied with $A$. carbo restriction (mf9), the probability increased from 9 to $98 \%$ in the short term and then remained stable for the whole period.

\subsubsection{Annual average variation in catch}

In the first year of projection, 2009, for almost all the stocks and scenarios, the adjustment in the catch was higher than $15 \%$ and in some cases higher than $50 \%$. Only for
M. dypterygia and A. carbo were there two scenarios where the adjustment was lower than $15 \%(\mathrm{mf} 1$ and $\mathrm{mf} 3$ for M. dypterygia and $\mathrm{mf} 10$ and $\mathrm{mf} 11$ for A. carbo). For A. carbo and Pollachius virens stocks, the variation was always negative and for the rest it depended on the scenario. In the scenarios where sharks were the restrictors $(\mathrm{mf} 5, \mathrm{mf} 6, \mathrm{mf} 7$ and $\mathrm{mf} 8$ ) and in the scenario when profits were maximized with M. dypterygia as restrictor ( $\mathrm{mf} 2$ ), the variation was also always negative. In the short term, 2010-2014, there were few cases 
Table 3. Probability of negative profits (A) and annual average variation (B) in effort in 2009 and the average of these indicators in the periods 2010-2014, 2015-2019 and 2020-2025.

\begin{tabular}{|c|c|c|c|c|c|c|c|c|c|c|}
\hline \multirow{2}{*}{ Scenario } & \multirow{2}{*}{\multicolumn{2}{|c|}{ Description }} & \multicolumn{4}{|c|}{ (A) Probability of negative profits } & \multicolumn{4}{|c|}{ (B) Average effort variability } \\
\hline & & & 2009 & 2010-2014 & 2015-2019 & $2020-2025$ & 2009 & 2010-2014 & 2015-2019 & $2020-2025$ \\
\hline mf0 & & Status quo effort & 1 & 0.97 & 0.94 & 0.93 & 0.05 & 0 & 0 & 0 \\
\hline $\mathrm{mf} 1$ & & Fcube + ICES & 1 & 0.95 & 0.93 & 0.88 & 0.51 & -0.06 & 0.01 & 0 \\
\hline $\mathrm{mf} 2$ & M. dypterygia & $\mathrm{MCP}+\mathrm{ICES}$ & 0.63 & 0.14 & 0.01 & 0.01 & -0.91 & 0.23 & 0.04 & 0.05 \\
\hline $\mathrm{mf} 3$ & restriction & Fcube + XSA + ICES & 1 & 0.95 & 0.92 & 0.79 & 0.51 & 0.07 & 0.01 & -0.02 \\
\hline $\mathrm{mf} 4$ & & Fcube + Annex IV & 1 & 1 & 1 & 1 & 0.51 & 0.13 & 0 & 0 \\
\hline mf5 & & Fcube + ICES & 0.96 & 0.70 & 0.21 & 0.07 & -0.65 & 0.02 & -0.03 & 0.00 \\
\hline mf6 & Shark & $\mathrm{MCP}+T A C_{\mathrm{SKH}}=500 \mathrm{t}$ & 0.63 & 0.12 & 0.01 & 0.01 & -0.91 & 0.24 & 0.03 & 0.03 \\
\hline mf7 & restriction & $\mathrm{MCP}+T A C_{\mathrm{SKH}}=1500 \mathrm{t}$ & 0.63 & 0.12 & 0.01 & 0.01 & -0.91 & 0.26 & 0.06 & 0.03 \\
\hline mf8 & & $\mathrm{MCP}+T A C_{\mathrm{SKH}}=2500 \mathrm{t}$ & 0.63 & 0.12 & 0.01 & 0 & -0.91 & 0.25 & 0.06 & 0.03 \\
\hline mf9 & A. carbo & Fcube + ICES & 0.88 & 1 & 1 & 1 & -0.94 & 10.76 & 0 & 0 \\
\hline $\operatorname{mf} 10$ & restriction & Fcube + Annex IV & 0.88 & 0.75 & 0.30 & 0.14 & -0.94 & -0.24 & -0.01 & 0.01 \\
\hline $\mathrm{mf} 11$ & C. rupestris & Fcube + ICES & 1 & 0.47 & 0.57 & 0.56 & 2.26 & -0.20 & 0.03 & 0 \\
\hline $\mathrm{mf} 12$ & restriction & Fcube + Annex IV & 1 & 1 & 1 & 0.95 & 2.26 & 0 & 0 & 0 \\
\hline
\end{tabular}

where the catch varied more than $15 \%$ and only one where it varied more than $50 \%$ (sharks in the mf9 scenario). From 2015 , the variation was lower than $15 \%$ for all the stocks and scenarios (Table S4).

\subsubsection{Probability of negative profits and annual average variation in effort}

Probability of negative profits and annual average variation in effort are shown in Table 3. In 2009, the probability of negative profits was high $>60 \%$ ) in all the scenarios. Low probability of negative profits $(<5 \%)$ was only obtained from 2015 onwards in the scenarios where profits were maximized (mf2, mf6, $\mathrm{mf} 7$ and $\mathrm{mf} 8$ ).

The probability of negative profits was $100 \%$ in the status quo scenario (mf0), in the scenarios where $M$. dypterygia was the restrictor stock and profits were not maximized ( $\mathrm{mf} 1, \mathrm{mf} 3$ and $\mathrm{mf} 4$ ), in the scenario where A. carbo was the restrictor and ICES HCR was used ( $\mathrm{mf9}$ ) and in the scenario where $C$. rupestris was used as restrictor combined with Annex IV HCR (mf12). In the rest of the scenarios (mf5, mf10 and mf11) the probability decreased with time, but the decrease level varied with the scenario. In the scenarios with sharks and $A$. carbo as restrictors, the probability decreased up to 7 and $14 \%$, respectively, but when $C$. rupestris was the restrictor, it only reached $56 \%$.

As with catch the major adjustment in effort occurred in 2009 when the variation was higher than $50 \%$ in all the scenarios except the status quo scenario. Profits were maximized when sharks or A. carbo were the restrictors, and the adjustment was negative ( $\mathrm{mf} 2, \mathrm{mf} 5$ to $\mathrm{mf} 10$ scenario) and positive in the rest (mf0, $\mathrm{mf} 1, \mathrm{mf} 3, \mathrm{mf} 4, \mathrm{mf} 11$ and $\mathrm{mf} 12)$. When A. carbo was the restrictor and ICES HCR was used (mf9), the effort was multiplied by 10 . In the rest of the scenarios, the variation was lower than $25 \%$. Only three scenarios had negative variation in effort in the medium term: the scenarios with M. dypterygia, A. carbo and C. rupestris as restrictors combined with the Fcube dynamic and ICES HCR, Annex IV HCR and ICES HCR, respectively (mf1, mf10 and mf11). Finally, from 2015 there was minor variation in effort for all the stocks and scenarios.

\subsubsection{Effort share}

The effort share among the principal FL01 metiers is shown in Table 4. These metiers accounted for the $96 \%$ of the total effort in the historical period. The effort share in the scenarios where Fcube was used and in the status quo scenario was the same and equal to the average of the last three years. Effort share varied in scenarios where profits were maximized. In the first projection year, the effort share was the same in all maximum conditional profit (MCP) scenarios and the variation in total effort was also the same (Table 4); thus, the effort dynamic in those scenarios was not restrained for M. dypterygia or for the sharks. In 2010, the second year of projection, slight differences arose between the scenarios restrained by $M$. dypterygia and those restrained by sharks. After the initial adjustment and until 2018, the effort share maintained quite stable with minor differences among scenarios. In this year, the effort share in NEW6 metier increased in the scenarios restrained by sharks and with the highest TAC especially. The effort share decreased in the DEM4 metier. After 2018, the effort share in NEW6 metier in the scenario restrained by $M$. dypterygia increased steadily up to a $28 \%$. In the scenario with $T A C_{S K H}=500 \mathrm{t}$ after 2015, the effort share in DEM4 had a slight decreasing trend opposite to the increasing trend in NEW6. REF5 and NEW5 metiers, which had effort shares of $13 \%$ and $5 \%$, respectively, in the historical period almost disappeared in the projection. Something similar happened in the EDGE6 and OTHER6 metiers where the effort share decreased from a $23 \%$ and $21 \%$, respectively, in the historic period to a $3 \%$ in the last projection year.

\section{Discussion}

\subsection{Sebastes mentella}

S. mentella is an important commercial species classified as a threatened species in the Norwegian economic zone 
Table 4. Historic average of effort share for most important metiers and median effort share in 2009, 2010, 2018 and 2025.

\begin{tabular}{|c|c|c|c|c|c|c|c|c|}
\hline Metier & Code & Scenario & Description & $\begin{array}{l}\text { Historic } \\
\text { average }\end{array}$ & 2009 & 2010 & 2018 & 2025 \\
\hline \multirow{4}{*}{$\begin{array}{c}\text { Demersal } \\
\text { fishing in ICES } \\
\text { Subarea IV }\end{array}$} & \multirow{4}{*}{ DEM4 } & $\mathrm{mf} 2$ & Molva dypterygia & \multirow{4}{*}{0.33} & 0.79 & 0.88 & 0.83 & 0.64 \\
\hline & & mf6 & $T A C_{\mathrm{SKH}}=500 \mathrm{t}$ & & 0.79 & 0.86 & 0.84 & 0.81 \\
\hline & & $\mathrm{mf} 7$ & $T A C_{\mathrm{SKH}}=1500 \mathrm{t}$ & & 0.79 & 0.86 & 0.70 & 0.60 \\
\hline & & $\mathrm{mf} 8$ & $T A C_{\mathrm{SKH}}=2500 \mathrm{t}$ & & 0.79 & 0.86 & 0.67 & 0.58 \\
\hline \multirow{4}{*}{$\begin{array}{l}\text { Edge in ICES } \\
\text { Subarea VI }\end{array}$} & \multirow{4}{*}{ EDGE6 } & $\mathrm{mf} 2$ & Molva dypterygia & \multirow{4}{*}{0.23} & 0.05 & 0.03 & 0.03 & 0.02 \\
\hline & & mf6 & $T A C_{\mathrm{SKH}}=500 \mathrm{t}$ & & 0.05 & 0.04 & 0.04 & 0.03 \\
\hline & & $\mathrm{mf} 7$ & $T A C_{\mathrm{SKH}}=1500 \mathrm{t}$ & & 0.05 & 0.04 & 0.03 & 0.03 \\
\hline & & $\mathrm{mf} 8$ & $T A C_{\mathrm{SKH}}=2500 \mathrm{t}$ & & 0.05 & 0.04 & 0.03 & 0.03 \\
\hline \multirow{4}{*}{$\begin{array}{l}\text { Other deepwater } \\
\text { grounds in ICES } \\
\text { Subarea VI }\end{array}$} & \multirow{4}{*}{ OTHER6 } & $\mathrm{mf} 2$ & Molva dypterygia & \multirow{4}{*}{0.21} & 0.11 & 0.07 & 0.04 & 0.03 \\
\hline & & mf6 & $T A C_{\mathrm{SKH}}=500 \mathrm{t}$ & & 0.11 & 0.08 & 0.04 & 0.02 \\
\hline & & $\mathrm{mf} 7$ & $T A C_{\mathrm{SKH}}=1500 \mathrm{t}$ & & 0.11 & 0.08 & 0.05 & 0.04 \\
\hline & & $\mathrm{mf} 8$ & $T A C_{\mathrm{SKH}}=2500 \mathrm{t}$ & & 0.11 & 0.08 & 0.05 & 0.04 \\
\hline \multirow{4}{*}{$\begin{array}{l}\text { New grounds in } \\
\text { ICES Subarea VI }\end{array}$} & \multirow{4}{*}{ NEW6 } & $\mathrm{mf} 2$ & Molva dypterygia & \multirow{4}{*}{0.03} & 0.02 & 0.01 & 0.04 & 0.28 \\
\hline & & mf6 & $T A C_{\mathrm{SKH}}=500 \mathrm{t}$ & & 0.02 & 0.02 & 0.06 & 0.12 \\
\hline & & $\mathrm{mf} 7$ & $T A C_{\mathrm{SKH}}=1500 \mathrm{t}$ & & 0.02 & 0.02 & 0.12 & 0.31 \\
\hline & & mf8 & $T A C_{\mathrm{SKH}}=2500 \mathrm{t}$ & & 0.02 & 0.02 & 0.25 & 0.32 \\
\hline $\begin{array}{c}\text { Reference } \\
\text { deepwater } \\
\text { grounds* }\end{array}$ & REF5 & all & 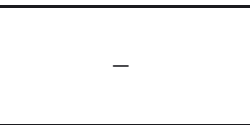 & 0.13 & \multicolumn{4}{|c|}{ \# 0} \\
\hline New grounds* & NEW5 & all & - & 0.04 & & & & \\
\hline
\end{tabular}

* in ICES Subarea V.

(ICES 2012). Since 2004, the recruitment of S. mentella has failed; nevertheless, data analysis from different cruises indicates an increase in recruitment in recent years (Planque et al. 2012). When $F_{m s y}=0.065$ is applied (following the ICES 2012 recommendation) in our model, results show similar projection patterns of $S S B$ as when using a Bayesian statistical catch-at-age method; a decrease in SSB until 2015, then an increase. This could be due to the maturation of the successful 1991 recruitment. However, uncertainty about the recruitment estimations of the last years is due to a few observations (Planque et al. 2012). Historical data of SSB with recruitment does not show any clear pattern in North East Atlantic S. mentella (ICES 2012). In the North West Atlantic, large-scale physical forces might have more control over the stock than the biological ones (Koslow 1984). Special caution should be taken in the interpretation of the projections of these methods due to the high uncertainty about the processes that govern $S$. mentella recruitment or survival.

\subsection{Pagellus bogaraveo}

Current management $(T A C=270 \mathrm{t})$ was sustainable for $P$. bogaraveo, even when implementation error was introduced into the simulation. When the advice was implemented correctly, the $S S B$ reached historical levels; however, when implementation error was introduced, historical levels were not reached.

Annex IV HCR and current management gave similar results. Observation error in the index when advice implementation was perfect had little effect and, when there was implementation error, the effect was positive for the stock. This HCR depends on the existence of a reliable abundance index, but the index used here is no longer available because the onboard observer programme ended in 2009. In the future, vessel monitoring system (VMS) information could be used as an alternative.

ICES HCR, under perfect knowledge of the biological population, gave satisfactory results. Under perfect implementation, the results were similar to current management and with implementation error the results were somewhat better. In the long term, the HCR with correct implementation produced similar catches to the case with implementation error; however, in the short term, the catch under correct implementation was significantly lower. Thus, a sacrifice in the short term would produce a similar level of catch in the long term under a significantly better stock status. However, to apply ICES HCR, estimates of exploitation level and biomass are needed in an assessment model. In this case, XSA was tested and did not work properly. Thus, in the absence of a robust assessment model, this HCR is not suitable as a management tool for this stock.

Current management was demonstrated to be almost as good as the alternative management based on HCRs, which depend on stock indicators. However, if the implementation of this management is considered in the future it would be necessary to have an alternative system to monitor stock status to be able to predict the possible collapse of the stock

\subsection{Mixed fisheries}

The profit and effort ranking almost coincide with the ranking of best to worst biological scenarios: "the higher the effort, the lower the profits and the worse the biological status of the stocks". The performances of the management strategies were highly driven by fleet dynamics. Best results, both biological and economic, were obtained when FL01 profits where maximized. This effort model was tested using $M$. dypterygia and 
sharks as restraining stocks. In the short term, the effort decreased sharply and FL01 did not even reach the quota share of these stocks, meaning that the management and the restrictor used were somewhat irrelevant in those years. The status quo scenario was not sustainable for $M$. dypterygia and $C$. rupestris and was not profitable in economic terms. The risk of collapse when XSA was used in the MP of M. dypterygia was much higher than when it was assumed that the real population was known correctly. Annex IV HCR did not work for $M$. dypterygia and C. rupestris but it did for A. carbo. ICES HCR performed better than Annex IV HCR for M. dypterygia and $C$. rupestris.

If the fleets followed profit maximization behaviour both biological and economic performance would improve. However, fishers do not always follow profit maximization (Salas and Gaertner 2004), and other factors not considered here could also contribute to fleet profit. In the present study, only five stocks were taken into account. The contribution, in value, of the stocks caught by FL01 and not considered here oscillates between 25 and $35 \%$ depending on the year. The inclusion of these stocks would change the economic performance of the fleet and optimum effort allocation would be different. A major part of the fishery was considered in an artificial way. Applying profit maximization to the whole fishery would have a great impact in both biological and economic results. A rigorous economic evaluation of the fishery should consider the inclusion of more stocks and the segmentation of the whole fishery.

The results obtained here differ from those obtained in Marchal et al. (2013). The modelling approaches differ mainly in the spatial dimension (not considered in the present study), the fleet dynamics and the reference points used. Whereas in Marchal et al. (2013), the results obtained using ICES MSY and Annex IV HCRs (referred as data-rich and data-poor HCRs respectively in Marchal et al. (2013)) are similar, in the present study there are significant differences. The fleet dynamics used in Marchal et al. (2013) have a tradition and a profit maximization component. A tradition component can be compared with an Fcube scenario where effort distribution follows average historical distribution. In turn, maximum profit scenario can be compared with the profit component. However, the key difference in the effort dynamics is how the total effort is calculated annually. In Marchal et al. (2013), the total effort is given by the annual number of vessels obtained with the entry-exit model. Thus, the effort and hence the fishing mortality exerted by French fleet is not directly conditioned by the TAC obtained through the HCRs. French catches represent around $55 \%$ of the total catch so the HCR does not restrict more than half of the total fishing mortality. Total annual effort level obtained with Fcube and maximum profit approaches is restricted by the TAC advice; thus, our results cannot be directly compared to Marchal et al. (2013).

In summary, the performance of ICES HCR depended on the suitability of the assessment model fit. Annex IV HCR performed properly when the stock was healthy but failed when the stock was overfished, as observed in a previous generic evaluation of the rule (ICES 2010). Deepwater stocks with reliable assessments are scarce and many are overfished (Punt 2005; Sissenwine 2007; Clark 2009); alternative HCR are therefore needed for these cases. Constant TAC management would be an option but, without quantitative data, it is difficult to set a catch level appropriate in both biological and economic terms. Furthermore, if such a strategy is applied, alternative information would be needed to predict possible stock collapse. This study highlights the need for an HCR applicable in datapoor situations.

The results obtained are constrained by the conditioning of the operating models. A complete evaluation of a management plan should include an exhaustive and rigorous analysis of the uncertainty in the fishery system in order to incorporate all the plausible realities of the system in the evaluation (Rademeyer et al. 2007). The study presented here lays the foundation for a full evaluation of management plans for the case studies considered.

In order to make a realistic evaluation of management strategies in a mixed fisheries context, it is crucial to advance in the understanding of fleet dynamics. Thus, further investigation is needed in this part of fisheries modelling. As shown here and previously pointed out by others, fleet behaviour can render stock management ineffective (Wilen et al. 2002; Salas and Gaertner 2004; Branch et al. 2006): no matter how good a management strategy is, it will not work if the fishers do not comply with it.

Under management strategy evaluation, FLBEIA has proven to be a valid model to evaluate management strategies taking into account the biological and economic dimensions of the problem in a mixed fisheries context Furthermore, social and ecological variables could be included in the model if needed. Thus, it represents a step forward from single stock MSE to full ecosystem models.

Acknowledgements. This study was carried out with financial support from the Commission of the European Communities under the DEEPFISHMAN project (Grant agreement No. 227390) and from the Basque Country Government (Environment, Territorial Planning, Agriculture and Fisheries Department). The authors are very grateful to Fernando Gonzalez from Instituto Español de Oceanografia (Vigo, Spain), Sonia Sanchez and Eider Andonegi from AZTI-Tecnalia (Spain) and Benjamin Planque from Institute of Marine Research (Norway) for their valuable help in P. bogaraveo and S. mentella case studies. This is paper number 631 from the Marine Research Division (AZTI-Tecnalia).

\section{Supporting Information}

Table S1. Scenarios run in the Sebastes mentella case study.

Table S2. Scenarios run in the Pagellus bogaraveo case study. Table S3. Scenarios run in French mixed-fisheries case study. Table S4. Annual average variation in catch in 2009 and in the three periods 2010-2014, 2015-2019 and 2020-2025.

\section{References}

Bailey D.M., Collins M.A., Gordon J.D.M., Zuur A.F., Priede I.G., 2009, Long-term changes in deep-water fish populations in the northeast Atlantic: a deeper reaching effect of fisheries? Proc. R. Soc. B 276, 1965-1969.

Branch T.A., Hilborn R.W., Haynie A.C., Fay G., Flynn L., Griffiths J., Marshall K.N., Scheuerell J.M., Ward E.J., 2006, Fleet dynamics and fishermen behavior: lessons for fisheries managers. Can. J. Fish. Aquat. Sci. 63, 1647-1668. 
Caddy J., 1998, A short review of precautionary reference points and some proposals for their use in data-poor situations. FAO Fisheries Technical Paper, Rome, No. 379.

Clark M.R., 2009, Deep-sea seamount fisheries: a review of global status and future prospects Lat. Am. J. Aquat. Res. 37, 501-512.

Cobb C.W., Douglas P.H., 1928, A theory of production. Am. Econ. Rev. 18, 139-165.

Curtin R., Prellezo R., 2010, Understanding marine ecosystem based management: a literature review. Mar. Policy 34, 821-830.

De la Mare W.K., 1998, Tidier fisheries management requires a new MOP (management-oriented paradigm). Rev. Fish. Biol. Fish. 8, 349-356.

EC, 2002, Council Regulation (EC) No. 2340/2002 fixing for 2003 and 2004 the fishing opportunities for deep-sea fish stocks. Official Journal of the European Union L 356.

FAO, 2009, International guidelines for the management of deep-sea fisheries in the high seas, Rome.

Forbes C., Evans M., Hastings N., Peacock B., 2000, Statistical distributions. New York, Wiley.

Gil J., 2006, Biologia y pesca del voraz, Pagellus bogaraveo (Brünnich, 1768), en el Estrecho de Gibraltar. Faculty of sea and environmental sciences, University of Cadiz.

Gordon J.D.M., O.A. Bergstad, I. Figueiredo, G. Menezes, 2003, The deep-water fisheries of the Northeast Atlantic: I Description and current trends. J. Northw. Atl. Fish. Sci. 31, 137-150.

Hauge K.H., Nielsen K.N., Korsbrekke K., 2007, Limits to transparency exploring conceptual and operational aspects of the ICES framework for providing precautionary fisheries management advice. ICES J. Mar. Sci. 64, 738-743.

ICES, 1998, Report of the Study group on the biology and assessment of deep-sea fisheries resources. ICES CM 1998/ACFM:12

ICES, 2005, Report of the ICES Advisory Committee on Fisheries Management, Advisory Committee on the Marine Environment and Advisory Committee on Ecosystems. ICES Advice 10.

ICES, 2010, Technical Background Evaluation of Annex IV Rules ICES CM 2010/ACOM: 58

ICES, 2011, Report of the Working Group on the Assessment of Demersal Stocks in the North Sea and Skagerrak (WGNSSK), Copenhaguen.

ICES, 2012. Report of the Arctic Fisheries Working Group, 20-26 April 2012, Copenhagen. ICES CM 2012/ACOM:05.

ICES, 2012. Report of the working group on the biology and assessment of deep-sea fisheries resources (WGDEEP), ICES CM 2012/ACOM: 17.

ICES, 2012, WKFRAME-3. Report of the Workshop on Implementing the ICES Fmsy Framework.

Iriondo A., García D., Santurtún M., Castro J., Quincoces I., Lehuta S., Mahévas S., Marchal P., Tidd A., Ulrich C., 2012, Managing mixed fisheries in the European western waters: application of Fcube methodology. Fish. Res. 134-136, 6-16.

Ives M.C., Scandol J.P., 2013, BIOMAS: A bio-economic modelling and assessment system for fisheries management strategy evaluation. Ecol. Model. 249, 42-49.

Jardim E., Urtizberea A., Motova A., Osio C., Ulrich C., Millar C., Mosqueira I., Poos J.J., Virtanen J., Hamon K., Carvalho N., Prellezo R., Holmes S., 2013, Bioeconomic modelling applied to fisheries with R/FLR/FLBEIA. JRC Scientific and Policy Report EUR 25823 EN.
Kell L.T., Mosqueira I., Grosjean P., Fromentin J.-M., Garcia D., Hillary R., Jardim E., Mardle S., Pastoors M.A., Poos J.J., Scott F., Scott R.D., 2007, FLR: an open-source framework for the evaluation and development of management strategies. ICES J. Mar. Sci. 64, 640-646.

Koslow J. A., 1984, Recruitment patterns in Northwest Atlantic fish stocks. Can. J. Fish. Aquat. Sci. 41, 1722-1729.

Large P.A., Agnew D.J., Álvarez Pérez J.Á., Barrio Froján C., Cloete R., Damalas D., Dransfeld L., Edwards C.T.T., Feist S., Figueiredo I., González F., Herrera J.G., Kenny A., Jakobsdóttir K., Longshaw M., Lorance P., Marchal P., Mytilineou C., Planque B., Politou C.-Y., 2013, Strengths and weaknesses of the management and monitoring of deep-water stocks, fisheries, and ecosystems in various areas of the world - A roadmap toward sustainable deep-water fisheries in the Northeast Atlantic? Rev. Fish. Sci. 21, 157-180.

Marchal P., De Oliveira J.A.A., Lorance P., Baulier L., Pawlowski L., 2013, What is the added value of including fleet dynamics processes in fisheries models? Can. J. Fish. Aquat. Sci. 70, 9921010.

Marchal P., Vermard Y., 2013, Evaluating deepwater fisheries management strategies using a mixed-fisheries and spatially explicit modelling framework. ICES J. Mar. Sci. 70, 768-781.

Pikitch E.K., Santora C., Babcock E.A., Bakun A., Bonfil R., Conover D.O., Dayton P., Doukakis P., Fluharty D., Heneman B., Houde E.D., Link J., Livingston P.A., Mangel M., McAllister M.K., Pope J., Sainsbury K.J., 2004, Ecosystem-based fishery management. Science 305, 346-347.

Planque B., Bellier E., Loots C., 2011, Uncertainties in projecting spatial distributions of marine populations. ICES J. Mar. Sci. 68, $1045-1050$.

Planque B., Johannesen E., Drevetnyak K.V., Nedreaas K.H., 2012, Historical variations in the year-class strength of beaked redfish (Sebastes mentella). ICES J. Mar. Sci. 69, 547-552

Punt A.E., 2005, The challenges of, and future prospects for, assessing deepwater marine resources: experience from Australia, New Zealand, Southern Africa and the United States. In: Shotton R., edn. Deep sea 2003: conference on the governance and management of deep-sea fisheries Part 1. Conference papers. FAO Fish. Proc., No. 3/1, pp., 138-148.

Punt A.E., Donovan G.P., 2007, Developing management procedures that are robust to uncertainty: lessons from the International Whaling Commission. ICES J. Mar. Sci. 64, 603-612.

R Development Core Team, 2011, R: A Language and Environment for Statistical Computing, Vienna.

Rademeyer R.A., Plaganyi E.E., Butterworth D.S., 2007, Tips and tricks in designing management procedures. ICES J. Mar. Sci. 64, 618-625.

Roques S., Sévigny J.M., Bernatchez L., 2002, Genetic structure of deep-water redfish, Sebastes mentella, populations across the North Atlantic. Mar. Biol. 140, 297-307.

Salas S., Gaertner D., 2004, The behavioural dynamics of fishers: management implications. Fish Fish. 5, 153-167.

Shepherd J.G., 1999, Extended survivors analysis: An improved method for the analysis of catch-at-age data and abundance indices. ICES J. Mar. Sci. 56, 584-591.

Sissenwine M.P., Mace, P.M. , 2007, Can deep water fisheries be managed sustainably? Report and documentation of the expert consultation on deep-sea fisheries of the high seas. Bangkok, 21-23 November 2006. FAO Fisheries Report, Rome 838, 61-111. 
Stransky C., 2005, Geographic variation of golden redfish (Sebastes marinus) and deep-sea redfish (S. mentella) in the North Atlantic based on otolith shape analysis. ICES J.Mar. Sci. 62, 1691-1698.

Ulrich C., Reeves S.A., Vermard Y., Holmes S.J., Vanhee W., 2011, Reconciling single-species TACs in the North Sea demersal fisheries using the Fcube mixed-fisheries advice framework. ICES J. Mar. Sci. 68, 1535-1547.

van Putten I.E., Kulmala S., Thébaud O., Dowling N., Hamon K.G., Hutton T., Pascoe S., 2012, Theories and behavioural drivers underlying fleet dynamics models. Fish Fish. 13, 216-235.
Villasante S., Morato T., Rodriguez-Gonzalez D., Antelo M., Osterblom H., Watling L., Nouvian C., Gianni M., Macho G., 2012, Sustainability of deep-sea fish species under the European Union Common Fisheries Policy. Ocean Coast. Manage. 70 SI, 31-37.

Wilen J.E., Smith M.D., Lockwood D., Botsford L.W., 2002, Avoiding surprises: incorporating fisherman behavior into management models. Bull. Mar. Sci. 70, 553-575. 